\title{
XLII. On the measurement of timber
}

\section{Mr. W. Wiseman}

To cite this article: Mr. W. Wiseman (1823) XLII. On the measurement of timber , Philosophical Magazine Series 1, 61:299, 204-206, DOI: 10.1080/14786442308644300

To link to this article: http://dx.doi.org/10.1080/14786442308644300

曲 Published online: 29 Jul 2009.

Submit your article to this journal $2 \pi$

III Article views: 3

Q View related articles $₫$ 
XLII. On the Measurement of Timber. By Mr. W. WISETo the Editors of the Philosophical Magazine and Journal.

FINDING lately, in your Philosophical Magazine and Journal for December last*, a letter by Mr.William Gutteridge, in which he reprobates, urges a change in, and proposes a substitute for, the customary method of timber-measuring; I cannot refrain from offering a few observations on the occasion.

Experience teaches that suggested plausible alterations are, when adopted, not always improvements.

Mr. Gutteridge evidently proceeds on the supposition that the timber of these kingdoms, when measured for sale, is always in the round state (for, in his new scheme, the only transverse dimension he directs to be taken is the dianieter at the midlength, and the only content is the cylindric); whereas the fact is, that the far greater part is (what may be called) semisquared; that is, the transverse section is brought nearly to the figure of an octagon; consequently Mr. G.'s plan cannot, with any propriety, be applied to any timber of this description. And here, I am of opinion that a better or fairer method for semi-squared timber cannot be devised than the old quarter-girt; for, the nearer the timber is to a perfect square the nearer truth will be the content; and the further from a square, though the purchaser gets a larger quantity, he incurs greater expense in reducing it (as in general he must at using) to a square. The same observation extends to all round timber which is to be converted to the square form at using. But timber being, without doubt, sometimes used in the round state, it is necessary to lay down rules for ascertaining the true content thereof.

Again, granting argumenti causâ, that timber in general is in the round form, Mr. G. evidently proceeds on the supposition that no rules have hitherto been promulgated by which the true content of such round timber can be determined. This is not the fact. To my knowledge, sliding rules accompanied by precepts have been in circulation and constant use above 25 years, by which (having either the diameter or quarter girt at the middle) not only the cylindric, but also (having any two of the three diameters or quarter girts of the middle and ends) the true conical content of round tapering timber is found with the greatest "ease and brevity." So that the * Vol. LX. p. 418.

" shield 
" shield of protection to designing knavery," and the practice of "legerdemain," have long since fallen plump "to the ground."

I would here just observe, that timber so tapering that one diameter is above triple the other, is rarely found in practice. A tree may occur now and then, having that disparity of diameters; but it usually happens that the tree naturally divides itself by sudden swells into two or more distinct parts, and consequently must " be measured" duobus vel pluribus frustis.

I will supply the investigation of the principle, as relates to round timber, to which the abovementioned sliding rule is adapted.

Let $s$ denote half the sum, and $d$ half the difference of the extreme diameters of any tapering piece of timber; $l$ the length, and $p$ be $=\cdot 7854$.

Then, the diameters themselves being $s+d$ and $s-d$, the

formula $\frac{1}{3} p l \times \overline{(s+d)^{2}+(s-d)^{2}+\sqrt{s+d^{2} \times s-d^{2}}}=\frac{1}{3} p l \times$

$\overline{2 s^{2}+2 d^{2}+s^{2}-d^{2}}=\frac{1}{3} p l \times \overline{3 s^{2}+d^{3}}=p l s^{2}+\frac{1}{3} p l d^{2}$ expresses (as is well known) the true content. In which ( $s$ being the diameter at the midlength) $p l s^{2}$ is the cylindrical content, and $\frac{1}{3} p l d^{2}$ the difference between that and the true content. Now since 13.5405 in inches, is the diameter of that cylinder whose length and content in feet are always equal to each other, and since the contents of cylinders of the same length are in the duplicate ratio of their diameters; therefore $15.5405^{z}$ (the square of the diameter of the standard cylinder) $: l$ (its content) $:: s^{\mathbb{z}}$ (the square of the given diameter) : the cylindrical content required; and in the same way $13.5405^{3}: \frac{1}{3} l:: d^{2}:$ the difference, which added to the cylindrical, will give the true conical content. Now two logarithmic lines, sliding one upon the other as in sliding rules, one being of a double radius with respect to the other, will, it is plain, solve these analogies by an operation as short and easy as in the old mode; that is, the length $(l)$ on one line being set to 13.54 on the other (usually called the girt) line, the middle diameter $(s)$ on this last line will stand against the cylindrical content on the first line; and one-third of the length $\left(\frac{1}{3} l\right)$ on the first line being set to 13.54 on the other, the half difference of the two extreme diameters $(d)$ on the second line will stand against the quantity on the first line, which added, makes the true content.

In a similar way the true content can be obtained by this sliding rule, when, instead of the diameters, the corresponding 
quarter girts are given. The gauge point to which the length is to be set, instead of 13.54 , will be 10.635 . In fact, this sliding rule is adapted to many other uses, as to find the true content of octagonal, hexagonal, \&c. timber, \&c.

It is plain, from the above, that, were it necessary, tables could easily be constructed for every purpose to which sliding rules are applied.

In conclusion: I think I have shown, that the recognising Mr. G.'s "precepts" by act of parliament, and his "pledge," which, perhaps, he would find impossible to redeem, are alike unnecessary. I am, gentlemen, Your most obedient servant,

Portland-place, Hull, Feb. 25, 1823.

WM. WisemaN.

We have also received from Mr. Paul Newton a letter respecting Mr. Gutteridge's proposed plan for the measurement of timber. He observes, that by this plan "a national advantage is doubtless intended to be held out to us in our maritime capacity! Mr. G.'s plan is professedly in favour of the grower. Now is not this grower very frequently a Dane, a Norwegian; an American, \&c.; and is not Mr. G. zealous to enhance the price of that commodity (timber) for the benefit of the purchaser-the British? The expense of shipping would be greatly augmented on Mr. G's plan.

"If our shipping be worth 30 millions, according to our present mode of measuring and our present price of timber, \&c. this 'improved method' would compel us (cordage and other articles in proportionate advance) to pay at least 36 millions for our wooden roalls. Six extra millions would consequently issue from the Treasury and the purses of our merchants; three millions of which would, on a moderate computation, pass into the hands of Danes, Norwegians, and Americans. Thus Britons would lose three millions, in the single article of shipping, from a regard to a foreign grower. If it be true, that Great Britain and Ireland own at present about 12,000 merchantvessels, and employ annually upwards of 4000 foreign vessels, we may reasonably conclude that, in a few years, from the adoption of Mr. G.'s method, these numbers, as well as the nature of our intercourse with foreign nations, would be reversed; and I fear we should in that case transfer those useful partitions, the wooden roalls, to our neighbours."

Newark, Jan. 6, 1823.

Note.-Probably, whatever system of measuring prevails, the price will adapt itself to it.-EnIr. 